\title{
Particle backscatter and relative humidity measured across cirrus clouds and comparison with microphysical cirrus modelling
}

\author{
M. Brabec ${ }^{1}$, F. G. Wienhold ${ }^{1}$, B. P. Luo ${ }^{1}$, H. Vömel ${ }^{2}$, F. Immler ${ }^{2}$, P. Steiner ${ }^{3}$, E. Hausammann ${ }^{1}$, U. Weers ${ }^{1}$, and \\ T. Peter ${ }^{3}$ \\ ${ }^{1}$ Institute for Atmospheric and Climate Science, ETH, Zurich, Switzerland \\ ${ }^{2}$ Deutscher Wetterdienst, Meteorologisches Observatorium Lindenberg, Germany \\ ${ }^{3}$ Federal Office of Meteorology and Climatology MeteoSwiss, Switzerland
}

Correspondence to: F. G. Wienhold (frank.wienhold@env.ethz.ch)

Received: 23 March 2012 - Published in Atmos. Chem. Phys. Discuss.: 13 April 2012

Revised: 6 September 2012 - Accepted: 10 September 2012 - Published: 5 October 2012

\begin{abstract}
Advanced measurement and modelling techniques are employed to estimate the partitioning of atmospheric water between the gas phase and the condensed phase in and around cirrus clouds, and thus to identify in-cloud and outof-cloud supersaturations with respect to ice. In November 2008 the newly developed balloon-borne backscatter sonde COBALD (Compact Optical Backscatter and AerosoL Detector) was flown 14 times together with a CFH (Cryogenic Frost point Hygrometer) from Lindenberg, Germany $\left(52^{\circ} \mathrm{N}\right.$, $\left.14^{\circ} \mathrm{E}\right)$. The case discussed here in detail shows two cirrus layers with in-cloud relative humidities with respect to ice between $50 \%$ and $130 \%$. Global operational analysis data of ECMWF (roughly $1^{\circ} \times 1^{\circ}$ horizontal and $1 \mathrm{~km}$ vertical resolution, 6-hourly stored fields) fail to represent ice water contents and relative humidities. Conversely, regional COSMO7 forecasts $(6.6 \mathrm{~km} \times 6.6 \mathrm{~km}, 5$-min stored fields) capture the measured humidities and cloud positions remarkably well. The main difference between ECMWF and COSMO data is the resolution of small-scale vertical features responsible for cirrus formation. Nevertheless, ice water contents in COSMO-7 are still off by factors $2-10$, likely reflecting limitations in COSMO's ice phase bulk scheme. Significant improvements can be achieved by comprehensive size-resolved microphysical and optical modelling along backward trajectories based on COSMO-7 wind and temperature fields, which allow accurate computation of humidities, homogeneous ice nucleation, resulting ice particle size distributions and backscatter ratios at the COBALD wavelengths. However, only by superimposing small-scale temperature fluctuations, which remain unresolved by the numerical weather
\end{abstract}

prediction models, can we obtain a satisfying agreement with the observations and reconcile the measured in-cloud nonequilibrium humidities with conventional ice cloud microphysics. Conversely, the model-data comparison provides no evidence that additional changes to ice-cloud microphysics - such as heterogeneous nucleation or changing the water vapour accommodation coefficient on ice - are required.

\section{Introduction}

Water vapour is a key element in the Earth's climate, weather and atmospheric chemistry. Dehydration mechanisms driven by the formation of visible and subvisible cirrus clouds, determine the atmospheric water vapour budget and thus the chemical and radiative properties of the upper troposphere and stratosphere. Though still uncertain, the role of cirrus clouds is of particular importance in the Earth's climate system due to their poorly characterized radiative properties and microphysics (Christensen et al., 2007). Approximately $30 \%$ of the Earth is covered with cirrus clouds, which influence the radiative budget by altering both the reflectivity for incoming solar radiation and the emission of outgoing infrared radiation (Joos et al., 2008). These characteristics motivate cirrus cloud studies.

At times surprisingly high supersaturations inside and around cirrus clouds have been measured, as if the nucleation of ice particles or the uptake of water onto the existing ice surfaces were hindered (e.g., Peter et al., 2006; Krämer et al., 2009; Jensen et al., 2008; Kahn et al., 2009; 
Murray et al. (2010); and references in these papers). Most of these observations have been performed on board of aircraft. However, high supersaturations in cirrus clouds have also been found by balloon-borne sondes, e.g. during the HIBISCUS campaign (Pommereau et al., 2011), detecting ice particles with a balloon-borne microjoule lidar (Di Donfrancesco et al., 2006) and humidity with a diode laser spectrometer (Durry et al., 2006). These measurements aimed at cirrus clouds forming in the outflow of large and persistent subtropical convective regions (Fierli et al., 2008).

A search for similar conditions, but in the convectively largely unperturbed midlatitude upper troposphere, was one goal of the "Lindenberg Upper-Air Methods Intercomparison" (LUAMI, 2008). This campaign took place at the meteorological observatory at Lindenberg, Germany $\left(52.21^{\circ} \mathrm{N}\right.$, $\left.14.12^{\circ} \mathrm{E}\right)$. In the present case study we focus on a sounding on 6 November 2008 with profiles of water vapour and particle backscatter measured by the Cryogenic Frost point Hygrometer (CFH) and the newly developed backscatter sonde (COBALD), respectively. These data are evaluated in the present analysis, and the COBALD-CFH tandem is shown to be an excellent payload for cirrus measurements.

$\mathrm{CFH}$ provides accurate measurements at cirrus altitudes (Vömel et al., 2007; Möhler et al., 2009; Thornberry et al., 2011). One of the shortcomings of previous radiosonde data is the lack of knowledge whether the measurements took place in clear sky or in cirrus clouds (Spichtinger et al., 2005a). COBALD's application as a cloud detector provides this information, proving the backscatter sonde to be an essential tool (Wienhold, 2011). Here we analyze the COBALD-CFH cirrus cloud data by means of a detailed case study. First, we use the measurements to explore the ability of global and regional numerical weather prediction (NWP) models to represent microphysical processes in cold, high cirrus clouds. To this end relative humidities and ice water contents from global ECMWF analysis data $\left(1^{\circ} \times 1^{\circ}\right.$ spatial resolution, 6-hourly stored fields, allowing for ice supersaturation according to Tompkins et al., 2007) and regional COSMO-7 forecasts $(6.6 \mathrm{~km} \times 6.6 \mathrm{~km}, 5$-min stored fields; MeteoSwiss, 2012) are directly compared with the measurements. This is an acid test for these models, given the faint nature of the subvisible cirrus clouds (optical depths $\tau<0.03$; Sassen, 2002) investigated here. Second, we apply backward trajectories based on input wind, pressure and temperature fields obtained from COSMO-7 with a time resolution of 5 minutes to force a comprehensive microphysical box and column model (Luo et al., 2003a, b) to explore the more detailed cloud properties.

\section{Methods: Instrumentation, meteorological data and models}

This section provides technical information on the COBALD and CFH sondes, on the model data from ECMWF analy- ses, COSMO-7 forecast runs (Doms et al., 2011) and LAGRANTO, the "LAGRangian ANalysis TOol", a trajectory model (Wernli and Davies, 1997). Finally, the Zurich Optical and Microphysical Model (ZOMM), a Lagrangian box and column model (Luo et al., 2003a, b) is introduced, which is used to describe the microphysical cirrus processes in full size-resolution.

\subsection{Backscatter sonde COBALD}

COBALD is a newly developed lightweight backscatter sonde designed to be flown on operational weather balloons. It is based on similar principles as the Wyoming backscatter sonde of Rosen and Kjome (1991), which has been used extensively in field studies (e.g., Larsen et al., 1994; Rosen et al., 1997; Beyerle et al., 2001). COBALD uses two high power $(250 \mathrm{~mW})$ LEDs at wavelengths centred at $455 \mathrm{~nm}$ (blue) and $870 \mathrm{~nm}$ (infrared). A silicon detector measures the light scattered back at both wavelengths by air molecules, aerosol particles or cloud droplets and ice crystals. The data are analyzed based on the procedure developed by Rosen and Kjome (1991).

The backscatter raw signal is the sum of two contributions, the molecular (or "Rayleigh") contribution and the additional aerosol or particulate contribution. The backscatter ratio $(B S R)$ is obtained by normalizing the raw signal to the molecular scattering, derived from the ambient molecular number density, using the temperature and pressure measured by the pTu-sonde. Accordingly, the aerosol (or particle) backscatter is defined as $A B S R=B S R-1$.

Estimated maximum uncertainties in the infrared channel $B S R$ are about $1.3 \%$ or $5 \%$ at ground level or $10 \mathrm{~km}$ altitude, respectively, and about $0.2 \%$ or $1 \%$ at the same altitudes in the blue channel. This renders a proper characterization of the tropospheric background aerosol difficult. However, an estimate of $A B S R$ of cirrus clouds - even the very thin, subvisible ones - is hardly affected by these errors, yielding a maximum error of $10 \%$ (for $A B S R=1$ in the infrared channel).

\subsection{Cryogenic Frost point Hygrometer (CFH)}

The CFH was developed at the University of Colorado (Vömel et al., 2007), presenting a state-of-the-art balloonborne measurement technology for atmospheric water vapour. Its design is based on the older NOAA/CMDL frost point hygrometer, with improved accuracy. Frost point hygrometers operate by cooling a mirror, which is controlled with an opto-electronic feedback to maintain a constant layer of liquid or frozen condensate. The mirror temperature corresponds to the dew or frost point temperature $\left(T_{\text {mirror }}=T_{\text {dew }}\right.$ or $T_{\text {mirror }}=T_{\text {ice }}$ ) of the gas passing over the mirror depending on the physical state of the condensate (Wiederhold, 1997). 
We calculate relative humidity with respect to ice according to its definition:

$R H_{\text {ice }}=\frac{e_{\text {ice }}\left(T_{\text {mirror }}\right)}{e_{\text {ice }}\left(T_{\text {ambient }}\right)}$,

where $e_{\text {ice }}(T)$ is the saturation water vapour pressure over ice at temperature $T$. The functional dependence of the vapour pressure, $e_{\text {ice }}(T)$, is determined from the vapour pressure formula of Murphy and Koop (2005). The uncertainty of the frost point measurement, including an uncertainty of $0.2^{\circ} \mathrm{C}$ in the air temperature measurement, is approximately $0.5^{\circ} \mathrm{C}$ (Vömel et al., 2007). A conservative estimate of the overall uncertainty in the relative humidity covering our altitude range is $8 \%$ of the reported $\mathrm{RH}_{\text {ice }}$ value, i.e. $\Delta \mathrm{RH}_{\text {ice }}= \pm 8 \%$ at saturation and $\Delta \mathrm{RH}_{\mathrm{ice}}= \pm 10.4 \%$ at the maximum saturation ratio corresponding to $\mathrm{RH}_{\mathrm{ice}}=130 \%$ observed on 6 November 2008 above Lindenberg.

\subsection{COBALD and CFH synchronisation and response times}

COBALD and CFH were flown on the same payload, but with different telemetry. The COBALD and CFH data sets were both measured during ascent. The quality of their synchronization was additionally checked by means of the distinct upper edge of a boundary layer fog at about $950 \mathrm{hPa}$ (Fig. 1) that both instruments measure accurately, eliminating potential telemetry differences. While COBALD has a negligible response time, the response time of CHF may approach a few seconds under the low pressures in the upper troposphere, but certainly remains below $10 \mathrm{~s}$. Also the temperature and pressure sensors may develop response times of a few seconds, so that data should not be compared on the $1 \mathrm{~s}$ or $2 \mathrm{~s}$ scale. Therefore, 10-s average values are used in the present work, which take account of all possible synchronization effects. This results in a vertical resolution of the measurements of about $50 \mathrm{~m}$.

\subsection{Meteorological data}

Fields of horizontal and vertical winds, pressures, temperatures, specific humidities and ice water contents from global operational analyses performed by the European Centre for Medium Range Weather Forecast (ECMWF) with roughly $1^{\circ} \times 1^{\circ}$ horizontal and $1 \mathrm{~km}$ upper tropospheric vertical resolution have been stored every $6 \mathrm{~h}$ and compared with the sonde measurements on 6 November 2008. The ECMWF data fail to represent the measured ice water contents and relative humidities. Insufficient spatial and temporal resolutions are likely reasons for this deficiency.

Therefore we have also compared with regional COSMO7 from MeteoSwiss. COSMO-7 is based on the model COSMO of the "COnsortium for Small-scale MOdelling" (Doms et al., 2011). It is a non-hydrostatic limited-area model developed for operational and research applications

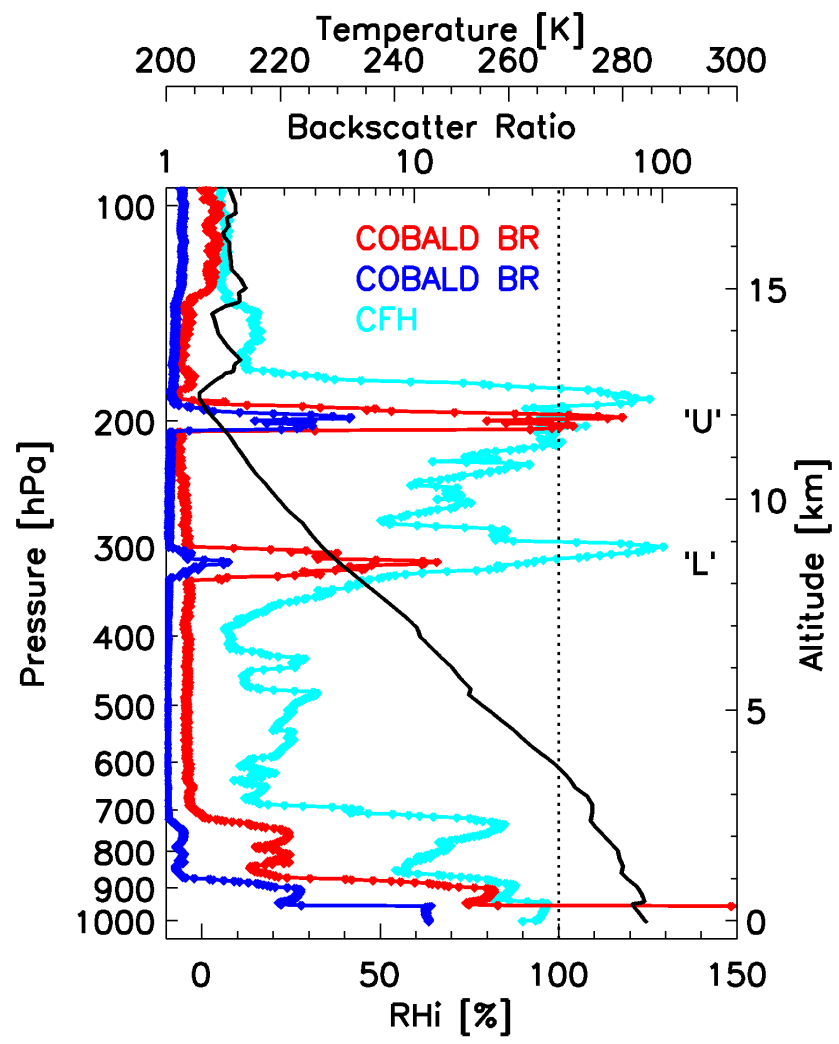

Fig. 1. Profile of balloon sounding on 6 November 2008 above Lindenberg, Germany. Blue and red lines: backscatter ratios $(B S R)$ at $455 \mathrm{~nm}$ and $870 \mathrm{~nm}$ wavelength, respectively, measured by COBALD. Cyan line: relative humidity with respect to ice $\left(\mathrm{RH}_{\mathrm{ice}}\right)$ obtained from the $\mathrm{CFH}$ frost point measurement. Quantities shown as function of barometric pressure and GPS-measured geometric altitude. The upper and lower cirrus clouds are termed " $U$ " and " $L$ ", respectively.

on the meso-beta and meso-gamma scale (Steppeler et al., 2003). The model is based on thermo-hydrodynamical equations describing compressible flow in a moist atmosphere. The model equations are formulated in rotated geographical coordinates and a generalized terrain following height coordinate. A variety of physical processes are taken into account by parameterization schemes (Doms et al, 2011). COSMO7 has $6.6 \mathrm{~km} \times 6.6 \mathrm{~km}$ horizontal and about $0.5 \mathrm{~km}$ vertical resolution in the upper troposphere. Instead of the hourly standard output we used high resolution output every $5 \mathrm{~min}$ (while the COSMO-7 internal time step is $60 \mathrm{~s}$ ) from one forecast (6 November 2008, 18:00 UTC) covering the region of interest.

\subsection{Trajectory calculation}

Trajectories are calculated with the three dimensional LAGRangian ANalysis TOol (LAGRANTO), which is explained in detail by Wernli and Davies (1997). LAGRANTO is forced by meteorological input data, e.g. from COSMO-7 
forecast wind fields. In LAGRANTO the forecast fields are interpolated linearly in space and time using the two nearest stored forecast fields. LAGRANTO has successfully been used in the past to investigate cirrus cloud processes (Colberg et al., 2003; Fueglistaler et al., 2004; Spichtinger et al., 2005b).

\subsection{Microphysical/optical column model}

We have employed the comprehensive microphysical box model (ZOMM) along COSMO-7-based LAGRANTO trajectories, in order to obtain the ice particle size distribution $(d n / d r)$ in full detail. The model simulates homogeneous ice nucleation and growth/evaporation including vapour diffusion and surface mass accommodation (while particle number densities are sufficiently small to render coagulation processes unimportant). In a pure box model configuration this model has previously been utilized for polar stratospheric cloud simulations (Luo et al., 2003b). With stacked boxes for the water vapour in the gas phase the model has also been used as a column model with a full treatment of particle sedimentation (Luo et al., 2003a). Here we use an approximation to the latter model, which treats sedimentation on a 50$\mathrm{m}$ vertical Eulerian grid spacing. The case investigated here is practically devoid of horizontal wind shear and is therefore well suited for a column approach. (Vertical wind shear may still compromise the model results; however, the lengthto-thickness aspect ratio of the cirrus clouds is sufficiently large to suggest quasi-uniform conditions along the cloud for ice particles sedimenting from the upper to the lower cloud edge.)

The particle model is Lagrangian in radius space for the condensed phase, i.e. the model follows the freshly nucleated particles and creates a new size class $(i)$ each time there is new ice particle nucleation. The model then transports the ice particles of class $i$ downstream with time-dependent radius $r_{i}(t)$ and constant number density, $n_{i}$. The model treats the vapour phase in an Eulerian scheme, with air parcels driven by temperature and pressure data along LAGRANTO trajectories. Upstream of the cloud, the air parcels are stacked in equal vertical distances of $50 \mathrm{~m}$ in the vertical column (this distance may change slightly downstream due to inhomogeneities in the vertical air motions) between $6 \mathrm{~km}$ and $14 \mathrm{~km}$. Also sedimentation of ice particles is treated in this Eulerian space, allowing the particles to sediment within the stacked column, i.e. a fraction of $n_{i}$ of class $i$ is removed according to the size-dependent sedimentation speed $v_{i}$ and reinjected to the box below. The sedimenting ice particles are then added in a mass and number conserving manner to two neighbouring size classes if the masses of ice particles differ by less than $20 \%$; otherwise, a new ice size class is created in the lower altitude grid spacing.

The microphysical column model performs a fully kinetic treatment of the ice particle size distribution including a partitioning of water between the vapour and condensed phases.
These calculations are based on the homogeneous ice nucleation parameterization by Koop et al. (2000) with updated homogeneous nucleation rate coefficient for pure water (Zobrist et al., 2007). Condensation/evaporation are calculated by solving the diffusion equation (including mass accommodation on the ice surface), which allows a much more detailed physical treatment than the equilibrium bulk cloud schemes used by ECMWF or in COSMO-7. The Lagrangian size treatment avoids "numerical diffusion", which may lead to artificial redistributions of particle number densities on a fixed Eulerian size grid. The treatment of sedimentation in the Eulerian grid space reintroduces some numerical diffusion; however, the tight vertical spacing $(50 \mathrm{~m})$ and the simultaneous mass and number conservation keep artefacts small. The initial aerosol particle distribution is chosen as lognormal with a mode radius $r_{\mathrm{m}}=0.06 \mu \mathrm{m}$, a lognormal width $\sigma=1.8$ and a total number density $n=200 \mathrm{~cm}^{-3}$, reflecting typical upper tropospheric aerosol size distributions at midlatitudes. The computations are initialized at suitable trajectory points upstream, where the underlying NWP suggests the air to be cloud-free (this procedure avoids having to initialize ice size distributions). Following Koop et al. (2000) homogeneous ice nucleation rates are calculated from saturation ratios $(\mathrm{RH})$ and temperature $(T)$ along each trajectory. Once formed, ice particles compete in uptake of water vapour from the gas phase at the expense of the liquid, diluted aerosol particles, similar to the Bergeron-Findeisen effect in mixed-phase clouds (Seinfeld and Pandis, 1998). The ice growth eventually depletes the vapour phase and relaxes the ice supersaturation. In combination with the nucleation scheme the diffusion limited treatment yields realistic ice particle number densities (Hoyle et al., 2005) and size distributions depending on the cooling rates prescribed by the trajectories, with the possibility to superimpose small-scale temperature fluctuations, $(d T / d t)_{s s}$.

Finally, an optical module uses the particle size distributions calculated by means of the microphysical model in order to calculate the backscatter ratios measured by COBALD at $455 \mathrm{~nm}$ (blue) and $870 \mathrm{~nm}$ (infrared). To this end, the backscatter of spherical particles, such as aerosol droplets and cloud drops, are computed in an exact manner by solving the scattering problem by means of a Mie code. Aspherical particles, such as ice crystals, are approximated as prolate ("cigar-like") spheroids with aspect ratio $A=a / b$ (the ratio of the equatorial to polar lengths) and volume $V=4 / 3 \pi a^{2} b$, which is set equal to the volume of the ice particles calculated by the microphysical model. Calculations were then made using a T-matrix light scattering algorithm (Mishchenko, 1991; Carslaw et al., 1998) with a refractive index of ice of 1.31 at 455 and $870 \mathrm{~nm}$ with spheroid shape. The ice particles are clearly aspherical. We have to make an assumption about the aspect ratio of the ice particles. Nousiainen and McFarquhar (2004) found that the small ice crystals with dimension $<100 \mu \mathrm{m}$ are mostly quasi-spherical. Fu (2007) found that the scattering properties are not sensitive 
the aspect ratio. We use a value of aspect ratio $A=0.75$ as approximation, which are not far from spherical shape. Also, while the degree of depolarization of light scattered back by aspherical particles depends crucially on their aspect ratio, the COBALD backscatter ratios, with which we compare below, depend only weakly on the assumed value of $A$ (by at most a factor 2.5 for particles with monodisperse $A \in[0.5$, 1.5], and more likely by less than $50 \%$ for broad $A$ distributions).

\section{Observations}

On 6 November 2008 just after 00:00 UTC the COBALD$\mathrm{CFH}$ tandem was launched on a radio sonde from Lindenberg as part of the LUAMI campaign. During this night northeastern Germany was covered by a $400-\mathrm{m}$ thick inversion layer with thick radiation fog, which rendered the employment of ground-based Lidars impossible. In addition to the optically thick radiation fog layer Fig. 1 shows two highaltitude cirrus clouds revealed by the COBALD and CFH measurements.

The upper tropospheric weather situation during this night is characterized by very little horizontal wind shear and wave-induced ice nucleation a few hours upstream, making it ideal for detailed testing of cirrus modelling. This is detailed in Figs. A1 and A2 of Appendix A.

The particle backscatter ratios and relative humidities $\mathrm{RH}_{\text {ice }}$ in Fig. 1 unambiguously reveal the two layers of subvisible cirrus clouds. Both cirrus layers have geometric thicknesses of about $600 \mathrm{~m}$ and optical thicknesses $\tau \leq 0.03$, i.e., they are "subvisible" according to the classification of Sassen (2002). The upper cirrus, "U", has a clearly defined lower edge at $11400 \mathrm{~m}$ and a less distinct upper edge. Inside and just below this cloud the gas phase is saturated with respect to ice (CFH measurements shown as cyan line), while a distinct layer extending from the upper cloud edge to roughly $500 \mathrm{~m}$ above the cloud reveals a supersaturation of up to $\sim 25 \%$. The lower cirrus layer, "L", has its lower edge at $8300 \mathrm{~m}$. Cloud "L" was reached at 0:36 UTC and cloud "U" at 00:44 UTC on 6 November 2008. Also cloud "L" shows a distinct layer with up to $\sim 30 \%$ supersaturation just above it and partly overlapping with the cloud, while the lower end of the cloud is subsaturated by $\sim 50 \%$ and presumably evaporating rapidly.

Without the COBALD measurements, i.e. based only on the $\mathrm{CFH}$ measurements, it would not be possible to determine the existence of a cloud, let alone the borders of the two cirrus clouds. For example, it would be impossible to reveal for cloud " $L$ " that half of the supersaturated layer is within the cloud and the other half above it, demonstrating that COBALD is essential for properly localizing and analyzing cirrus.

The observed clear-sky supersaturations of $30 \%$ are not surprising; for example homogeneous ice nucleation requires more than $45 \%$ supersaturation under midlatitude upper tropospheric conditions (Koop et al., 2000), and ice nuclei, when aged and coated with organics or sulfuric acid, may also have freezing thresholds between $130 \%$ and the homogeneous freezing threshold. The range of $\mathrm{RH}_{\text {ice }}=50 \%$ $130 \%$ inside the lower cirrus might be more surprising at first sight, but only detailed cloud modelling can help clarifying whether such non-equilibrium conditions are to be expected (see Sects. 5 and 6).

\section{Analyzing COSMO-7 fields}

Before comparing with COSMO-7, we have compared the measurements in Fig. 1 with the 00:00 UTC ECMWF operational analysis data above Lindenberg, Germany on 6 November 2008. However, the ECMWF analysis (including ice supersaturation according to Tompkins et al. (2007)) fails to generate the observed clouds or humidities: the ice water content $(I W C)$ is zero at any altitude at the time of the observation. The ECMWF analysis succeeds in obtaining realistic $\mathrm{RH}_{\text {ice }}$ in the vicinity of the upper cloud " $\mathrm{U}$ ", however, without triggering ice nucleation, and it completely misses the supersaturation close to the lower cloud "L". Backward trajectories based on the 6-hourly analysis output reveal that the air parcel ending at "L" had developed a cirrus cloud at 12:00 UTC on 5 November (with $I W C=0.018 \mathrm{~g} / \mathrm{kg}$ ), i.e. about $12 \mathrm{~h}$ before the sounding, but this cloud led to a too rapid dehydration of this layer, and the ice disappeared completely from the entire air column by the time of the measurement.

Figure 2 shows direct comparisons of the measurements with the COSMO-7 forecast results. The black lines in all four panels of Fig. 2 represent COSMO-7 forecast data above Lindenberg, Germany on 6 November 2008. Comparisons are shown for 00:35 (left) and 00:45 UTC (right panels), corresponding the encounters with "L" and "U", respectively. The cyan lines in the upper two panels represent $\mathrm{RH}_{\text {ice }}$ measured by $\mathrm{CFH}$ and the horizontal grey bars mark the cloud positions as deduced from the backscatter measurements.

A difficulty arises when we want to compare the backscatter ratios $(B S R)$ measured by COBALD with the COSMO$7 \mathrm{IWC}$, which is the only condensed phase quantity provided by the ice bulk scheme of the regional weather forecast model. The difficulty stems from the fact that the two BSR do not provide sufficient information to derive the complete size distribution, which would in principle be required for an exact derivation of the $I W C$. Clouds with the same $B S R$ at a given wavelength can have different $I W C$ if they have different particle sizes and number densities. However, as both the $I W C$ and a $B S R$ are integral measures of condensed water per volume of air, there is a robust relationship between the two, and only a weaker dependence on the details of the size distribution. Appendix B shows that a measurement of $B S R$ at $870 \mathrm{~nm}$ within a thin high cirrus cloud constrains its $I W C$ to 

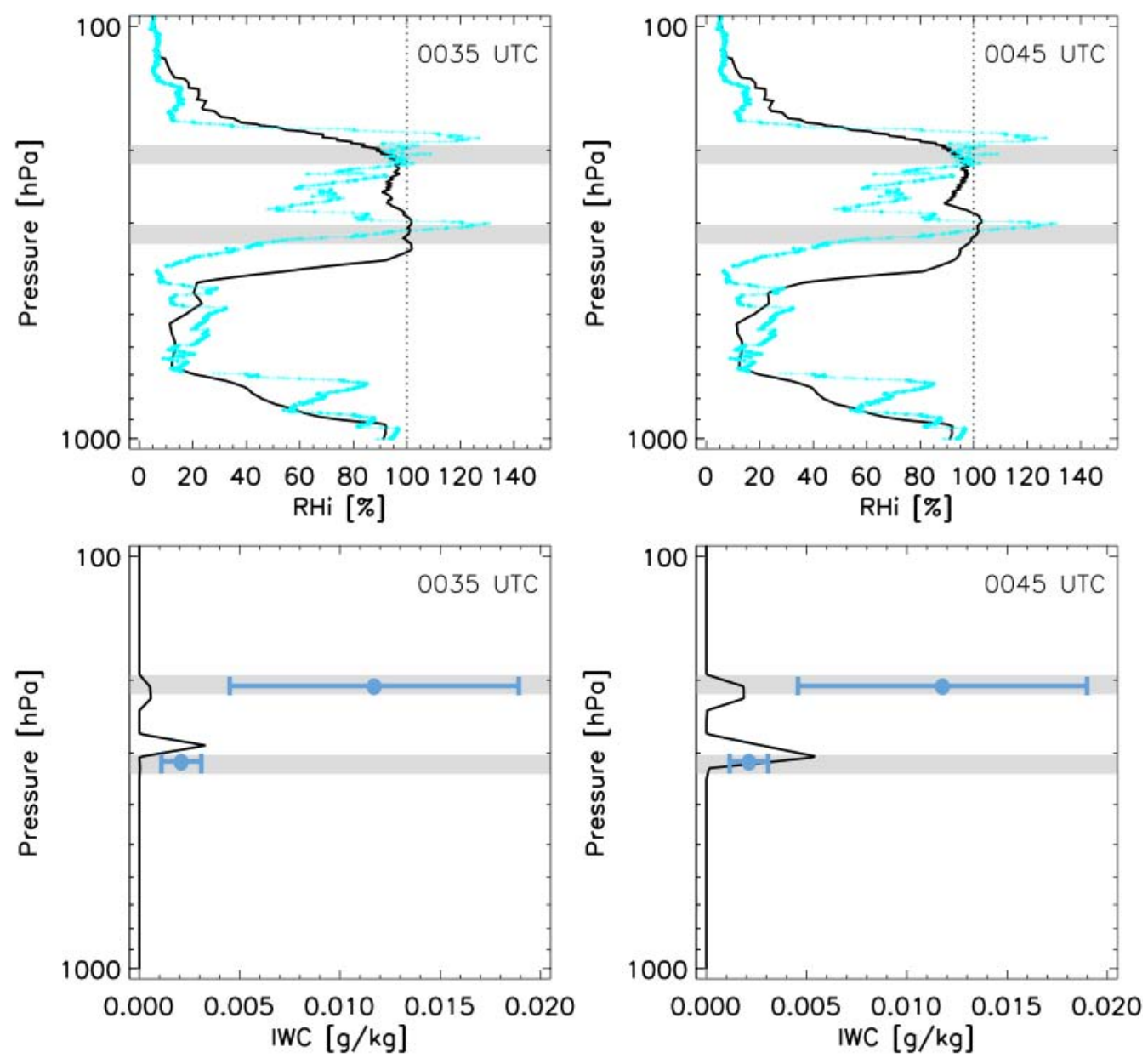

Fig. 2. $\mathrm{RH}_{\mathrm{ice}}$ and $I W C$ profiles of COSMO-7 forecast data (black lines) above Lindenberg on 6 November 2008. Left: sounding of lower cloud at 00:35 UTC. Right: sounding of upper cloud at 00:45 UTC. Cyan line: $\mathrm{RH}_{\mathrm{ice}}$ profile measured by CFH. Grey horizontal bars: altitude ranges of the detected clouds. Blue bars in the lower two panels: IWC estimated from COBALD data as explained in Appendix A.

within a factor of $\sim 4$. The blue points in the lower two panels of Fig. 2 show the estimation of the maximum $I W C$ within the clouds based on the maximum $B S R$ at $870 \mathrm{~nm}$ measured by COBALD, and the horizontal error bars show the uncertainties described above.

$\mathrm{RH}_{\text {ice }}$ from COSMO-7 data at 00:35 and 00:45 UTC in Fig. 2, while unable to provide the fine filamentary structure captured by $\mathrm{CFH}$, shows general features in agreement with the $\mathrm{CFH}$ measurement. In particular, COSMO-7 correctly represents the characteristic double hump in $\mathrm{RH}_{\text {ice }}$ with two layers of saturation or slight supersaturation; this is the basis for the development of two distinct cirrus layers. However, the modelled supersaturations do not reach the high values shown by CFH, probably because the lack of a kinetic treatment of ice particle growth empties the vapour phase too quickly. Furthermore, the modelled $\mathrm{RH}_{\text {ice }}$ profile appears to be shifted downward in comparison to the measurement, suggesting that the ice particles modelled by COSMO-7 might grow to too large sizes and therefore might sediment too rapidly.

The IWC of the COSMO-7 fields in the lower panels of Fig. 2 clearly display two cirrus clouds in agreement with COBALD. However, the upper cloud "U" resides at a too low altitude and the $I W C$ is much too small. The underestimation of $I W C$ is at least a factor of 2, more likely a factor of 5 (taking the uncertainties in the derivation of $I W C$ from the COBALD data into account).

\section{Trajectory-based microphysical analysis without small-scale $d T / d t$}

As described in Sections 2.4 and 2.5 we have used the microphysical column model, driven along LAGRANTO backward trajectories directly based on COSMO-7 forecast fields, i.e. without consideration of unresolved small-scale temperature fluctuations, $(d T / d t)_{s s}$. Panel (a) in Fig. 3 shows BSR at $870 \mathrm{~nm}$ during the last $8 \mathrm{~h}$ of these trajectories before 

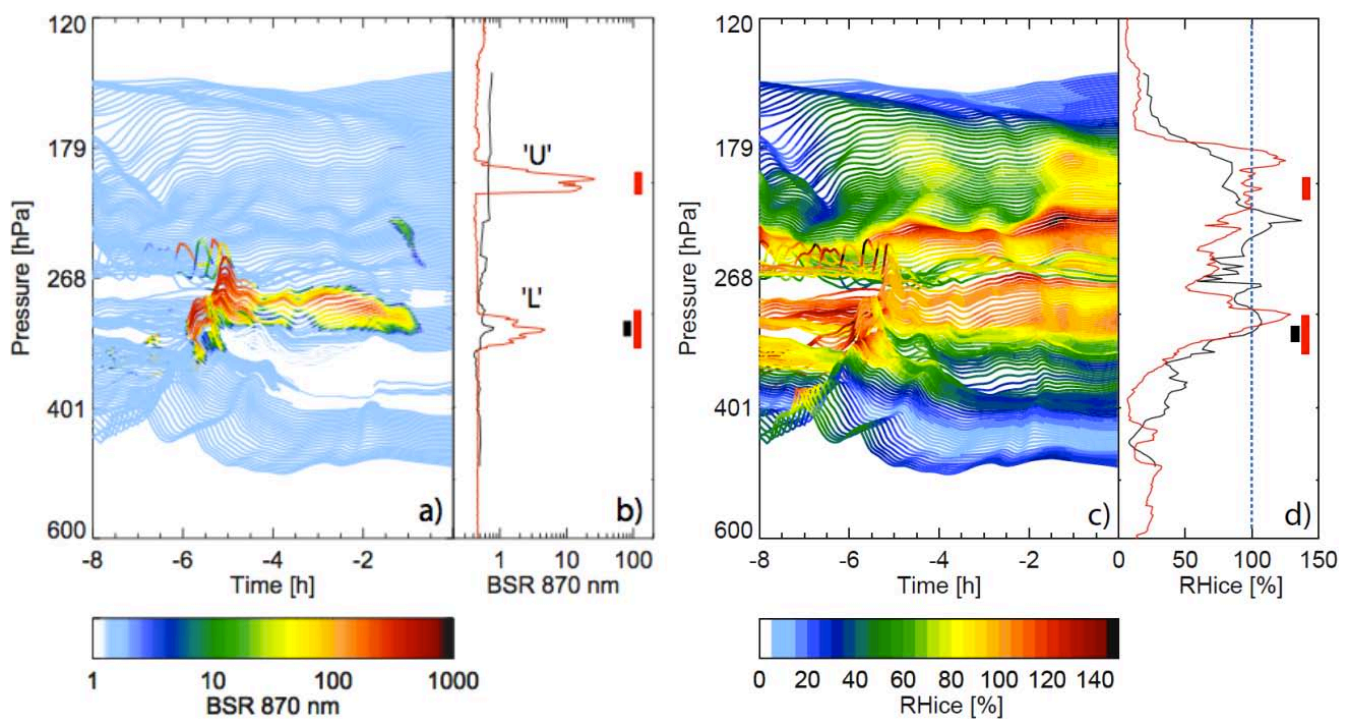

Fig. 3. Results from the microphysical column model ZOMM on LAGRANTO trajectories driven by COSMO-7 meteorological fields ( 5 min resolution) compared to measurements of backscatter ratio $(B S R)$ at $870 \mathrm{~nm}$ wavelength $(\mathbf{a}, \mathbf{b})$ and relative humidity $\left(\mathrm{RH}_{\mathrm{ice}}\right) \mathrm{with}_{\mathrm{i}}$ respect to ice (c, d). (a, c) Colour-coded: modelled BSR and $\mathrm{RH}_{\mathrm{ice}}$. (b, d) Red curves: BSR and $\mathrm{RH}_{\mathrm{ice}}$ profiles measured by COBALD and CFH, respectively; black curves: model results at $t=0$ above Lindenberg (right edge of (a) and (c)). The model produces both clouds ("U" and "L") a few hours upstream of the measurement, but due to too rapid sedimentation fails to maintain them until the measurement time. Red and black bars in (b) and (d) indicate the altitude ranges of the measured clouds and modelled cloud remnants, respectively.

arriving above Lindenberg (at $t=0$ ). The lower cloud "L" forms at $-6 \mathrm{~h}$ through homogeneous nucleation above the Upper Tauern mountain chain (see Appendix A). In the first few hours of lifetime of "L" the $B S R$ reaches values of more than 500, indicating an optically thick cirrus cloud. This is in accordance with the satellite images (Fig. A1 at $t=-5 \mathrm{~h}$ ). At around $t=-0.7 \mathrm{~h}$ the cloud has almost fully evaporated, leaving only a small remainder in the modelled $B S R$ profile (black line in panel (b) of Fig. 3), with an aerosol backscatter ratio $A B S R=B S R-1$ about 5 -times smaller than measured by COBALD (red line).

The upper cloud "U" starts to form only at $t=-1.5 \mathrm{~h}$, related to a slow upwelling of the air above the East German flatlands. However, the ice crystals sediment much too rapidly, and cloud "U" evaporates fully at $t=-0.6 \mathrm{~h}$. The high sedimentation rates are suggestive of too few, too large ice crystals that form in the microphysical column model along the COSMO-7-derived trajectories in the absence of $(d T / d t)_{s s}$. As a consequence, the model fails to reproduce the upper cloud.

\section{Trajectory-based microphysical analysis including small-scale $d T / d t$}

The results shown in Sect. 5 indicate that in order to reproduce the observed clouds it appears to be necessary to superimpose small-scale temperature fluctuations, $(d T / d t)_{s s}$, that remain unresolved by the mesoscale trajectories, as has also been suggested by Hoyle et al. (2005). In the following we will use $(d T / d t)_{s s}$ based on measurements from the "Subsonic Aircraft: Contrail and Cloud Effects Special Study" (SUCCESS). The procedure is similar to that employed by Hoyle et al. (2005). However, while these authors have superimposed $(d T / d t)_{s s}$ directly from the SUCCESS vertical wind measurements onto trajectories derived from ERA-40 6-hourly meteorological input fields with a coarse resolution of roughly $275 \mathrm{~km} \times 275 \mathrm{~km}$, we need to take into account that our COSMO-7 fields with $6.6 \mathrm{~km} \times 6.6 \mathrm{~km}$ every 5 min (see Appendix C) have a much better resolution, so that the larger scale fluctuations will already be included. Therefore, we performed a Fourier analysis of the SUCCESS data and kept only contributions to $(d T / d t)_{s s}$ corresponding to wavelengths smaller than $30 \mathrm{~km}$, as contributions with longer wavelengths will likely be fully resolved on the $6.6-\mathrm{km}$ grid of COSMO-7 (assuming that 4 grid points are required to resolve a wave-like feature). The remaining $(d T / d t)_{s s}$ are applied with a variance of $0.2 \mathrm{~K}^{2}$ (which corresponds a mean amplitude of about $0.45 \mathrm{~K}$ ) and random frequencies. Figure 4 shows one example, where the solid line represents the temperature along one COSMO-7-based LAGRANTO trajectory with the superimposed small-scale fluctuations shown as dotted line. The mean temperature variance used here is $0.2 \mathrm{~K}^{2}$. The mean temperature variance of $1.24 \mathrm{~K}^{2}$ derived by Hoyle et al. (2005) from a total of $300 \mathrm{~min}$ of SUCCESS measurements in cirrus clouds under background conditions (i.e. far off orographic perturbations) is only apparently larger, as it includes also waves with wavelengths $>30 \mathrm{~km}$. The mean temperature variance for waves with wavelengths $<30 \mathrm{~km}$ 


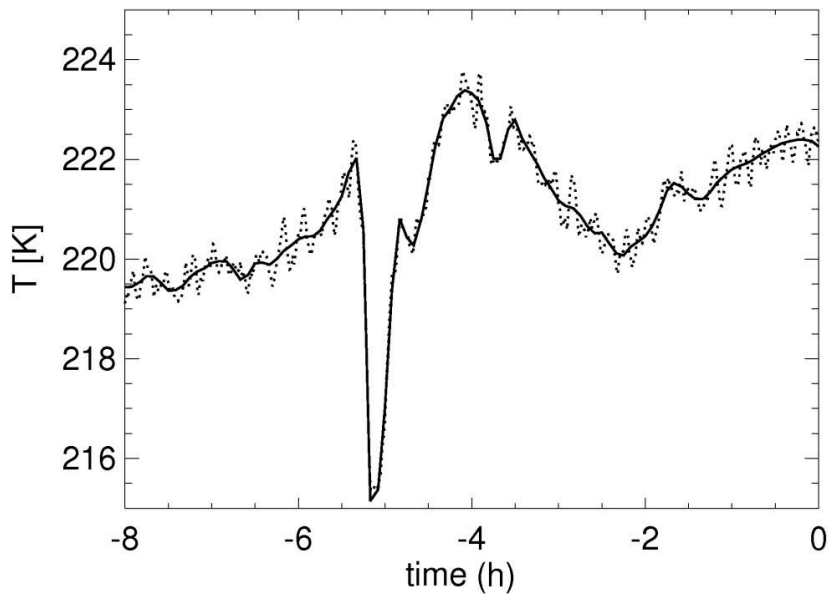

Fig. 4. Solid black line: temperature along a COSMO-7-based LAGRANTO trajectory in about $9 \mathrm{~km}$ altitude (close to cloud "L"). Dotted line: same trajectory with superimposed small-scale temperature fluctuations $(d T / d t)_{s s}$ (random superposition). The cooling rate spectrum has been determined from the variance $\left(0.2 \mathrm{~K}^{2}\right)$ and frequencies of $(d T / d t)_{s s}$ with wavelengths smaller than $30 \mathrm{~km}$ (see text) in agreement with the vertical wind measurements made during the SUCCESS campaign (see Hoyle et al., 2005).

measured during the SUCCESS campaign is indeed only $0.18 \mathrm{~K}^{2}$, i.e. only about $10 \%$ smaller than the value used in the present study.

Figure 5 shows results obtained from the microphysical column model driven along COSMO-7-based LAGRANTO trajectories with superimposed small-scale temperature fluctuations (see in addition Fig. B2). The left side of the figure shows BSR and how the ice crystals persist until the time of the measurement (panel a). This modelling approach develops two cloud layers and is overall a much more accurate description of the measurements than the result without $(d T / d t)_{s s}$ shown in Fig. 3. However, specific discrepancies remain. The modelled lower cloud " $\mathrm{L}$ " is geometrically only half as thick as observed, but the $B S R$ intensity is about 4 times larger at its peak (Fig. 5b). The modelled upper cloud "U" resides at an altitude about $1 \mathrm{~km}$ too low, but agrees well in intensity with the measurement.

The right side of Fig. 5 shows $\mathrm{RH}_{\text {ice }}$, which does not differ much from the results in Fig. 3. Panel (c) displays the evolution of $\mathrm{RH}_{\text {ice }}$ during the 8 hours before the measurement. Panel (d) shows that the general features of the modelled and measured $\mathrm{RH}_{\text {ice }}$ profiles agree reasonably, but the modelled values are somewhat too low in the vicinity of the upper cloud "U". The in-cloud measurements showed that $\mathrm{RH}_{\text {ice }}$ varied between $50 \%$ and $130 \%$. In contrast, the modelled in-cloud $\mathrm{RH}_{\text {ice }}$ covers only the range from $80 \%$ to $105 \%$, i.e. in the model sub- and supersaturations tend to relax too rapidly. For both clouds the profiles of $\mathrm{RH}_{\text {ice }}$ and $B S R$ are vertically displaced, i.e. the $B S R$ maxima are located below the $\mathrm{RH}_{\text {ice }}$ maxima (or actually sit close to the transition point of super- to subsaturation), which is likely due to particle sedimentation. This suggests a delicate interplay between $\mathrm{RH}_{\text {ice }}$ and $(d T / d t)_{s s}$ : in the absence of $(d T / d t)_{s s}$ ice number densities are small, particles grow to large sizes, sediment rapidly and allow for large deviations from saturation; conversely, with $(d T / d t)_{s s}$ ice number densities are generally larger, particle stay smaller, sediment less rapidly and lead to faster equilibrations of in-cloud sub- and supersaturations. Improved agreement between model and measurement might be achieved if the mass accommodation coefficient of the $\mathrm{H}_{2} \mathrm{O}$ molecules on the ice surface was assumed to be much smaller than unity (the value used in the present calculations) or was dependent on the degree of supersaturation (e.g. MacKenzie and Haynes, 1992). In order to test the dependence of the modelled cirrus on the superimposed $(d T / d t)_{s s}$ we performed an ensemble calculation with 20 runs using the microphysical column model and applying different temperature fluctuations obtained by random superpositions of different frequencies (but all with a variance of $0.2 \mathrm{~K}^{2}$ ). The results are displayed in Fig. 6 as blue lines, while the measurements are shown as red line. In general the 20 runs are very similar: 18 of the 20 runs produce two fully developed cloud layers, while 2 runs show only a marginal upper cloud (left panel), and $\mathrm{RH}_{\text {ice }}$ displays only small differences between the 20 runs (right panel). However, the left panel shows also that the position and width of the lower cloud vary in dependence on the way the temperature fluctuations are superimposed. The upper cloud is in all 20 cases too low in altitude, which is an error likely due to the COSMO-7 cloud scheme dehydrating the air too strongly in an upstream cloud event. Within all ensemble calculations incloud $\mathrm{RH}_{\text {ice }}$ cover the range from $70 \%$ to $130 \%$. Compared with with the observed variation between $50 \%$ and $130 \%$ this is in better agreement than the case detailed in Fig. 5, at least concerning the supersaturation. The still too small subsaturation might be an indication that the ice particles, after applying $(d T / d t)_{s s}$, are slightly too small and do not sediment sufficiently fast into dryer layers of air. Nevertheless, our measured and modelled in-cloud $\mathrm{RH}_{\text {ice }}$ are similar to the in-cloud $\mathrm{RH}_{\text {ice }}$ measured by Krämer et al. (2009) in the same temperature range.

Furthermore, we find a median ice number density of $0.03 \mathrm{~cm}^{-3}$ for the upper cloud and $0.31 \mathrm{~cm}^{-3}$ for the lower cloud, and for both clouds together a median of $0.20 \mathrm{~cm}^{-3}$ (see Fig. B2). Krämer et al. (2009) showed the observed ice number densities as function of temperature (their Figure 5), with a middle value of $\sim 0.15 \mathrm{~cm}^{-3}$ at $214 \mathrm{~K}$ and $\sim 0.25 \mathrm{~cm}^{-3}$ at $230 \mathrm{~K}$. The number densities obtained here are in good agreement with those of Krämer et al., but without having to invoke heterogeneous nucleation.

We emphasize that we performed the modelling without consideration of heterogeneous nucleation, but with $(d T / d t)_{s s}$. A significant influence of heterogeneous nucleation in our observations can be excluded, as otherwise the pronounced supersaturations above the cloud layers could 

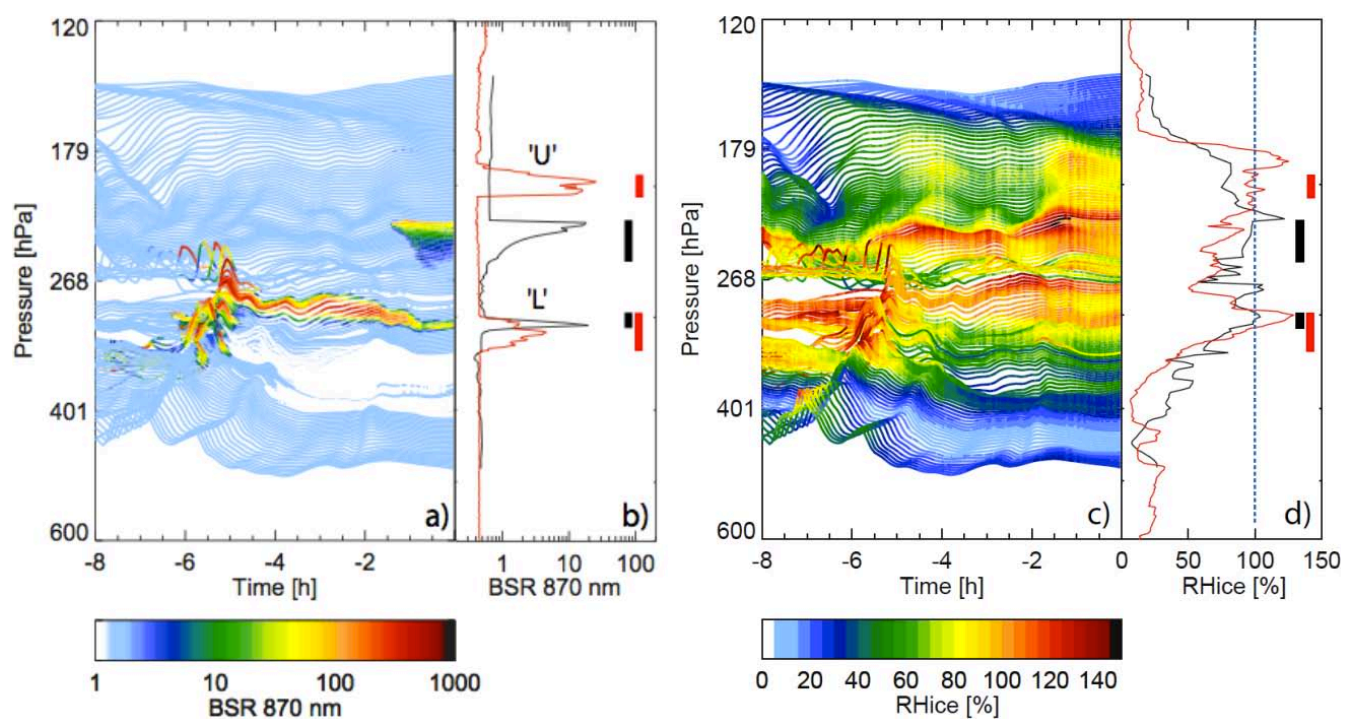

Fig. 5. Results from microphysical column model driven by COSMO-7-based LAGRANTO trajectories with superimposed small-scale temperature fluctuations $(d T / d t)_{s s}$ compared to measurements of backscatter ratio $(B S R)$ at $870 \mathrm{~nm}$ wavelength (a, b) and relative humidity $\left(\mathrm{RH}_{\mathrm{ice}}\right)$ with respect to ice (c, d). (a, c) Colour-coded: modelled $B S R$ and $\mathrm{RH}_{\mathrm{ice}}$ (b, d) Red curves: $B S R$ and $\mathrm{RH}_{\mathrm{ice}}$ profiles measured by COBALD and CFH, respectively; black curves: model results at $t=0$ above Lindenberg (right edge of (a) and (c)). The model produces both clouds ("U" and "L") a few hours upstream of the measurement, and due to $(d T / d t)_{s s}$ forms sufficiently small ice particles, which survive until the measurement time. Red and black bars in (b) and (d) indicate the altitude ranges of the measured and modelled clouds, respectively.
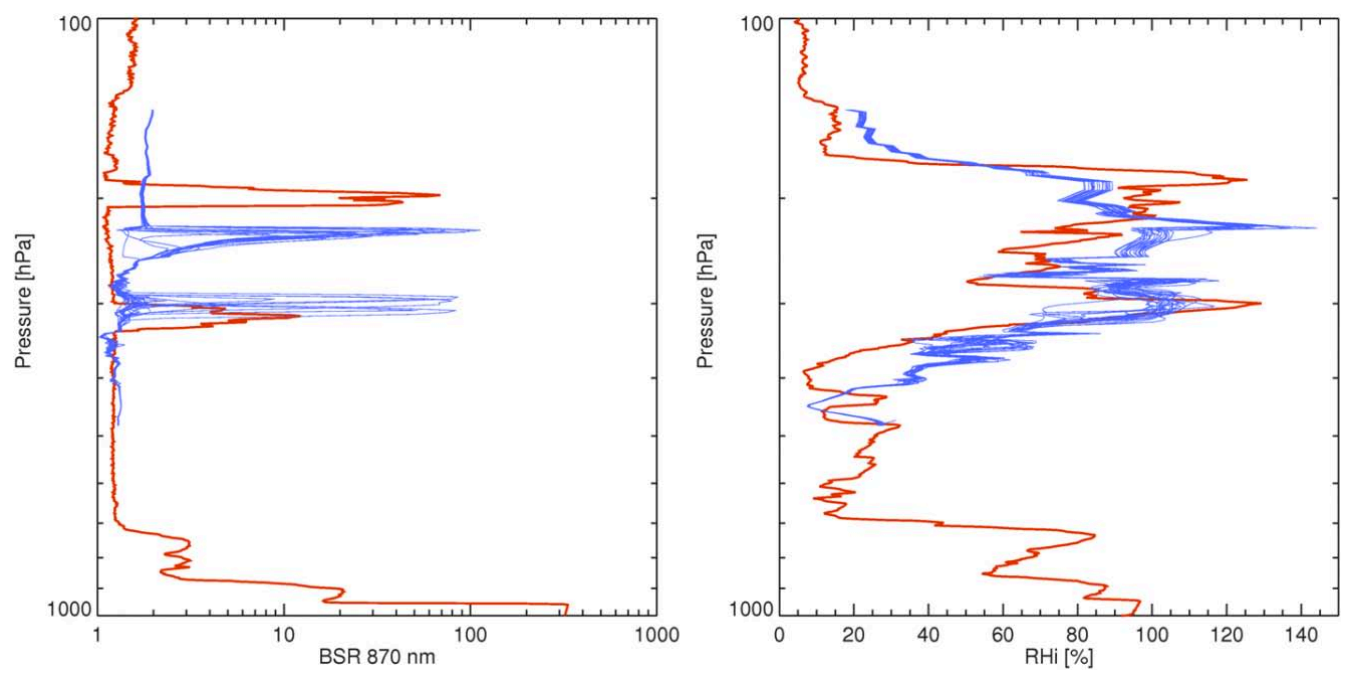

Fig. 6. Ensemble of 20 microphysical column model runs (blue) with superimposed small-scale fluctuations compared with the measurements (red). The left panel shows $B S R_{870}$ and the right $\mathrm{RH}_{\mathrm{ice}}$.

hardly survive (cp. Jensen et al., 2008). On the other hand we cannot fully exclude the presence of a few ice nuclei, which might have led to some limited formation of ice crystals before reaching the homogeneous nucleation threshold. Heterogeneous nucleation on a few ice nuclei leads generally to a reduction in $n_{\text {ice }}$ compared to having only homogeneous nucleation, since the few heterogeneously nucleating particles absorb disproportionately much water and leave less for the subsequent homogeneous nucleation (termed "negative
Twomey effect" by Kärcher and Lohmann (2003); see also Hoyle et al. (2005); Spichtinger and Cziczo (2010)). Heterogeneous nucleation would therefore counteract the effect of $(d T / d t)_{s s}$. Choosing the variance of $(d T / d t)_{s s}$ somewhat larger than $0.2 \mathrm{~K}^{2}$ could largely compensate the effect of heterogeneous nucleation with respect to $n_{\text {ice }}$. Clearly, with $(d T / d t)_{s s}$ not being sufficiently constrained, we see no need to introduce heterogeneous nucleation of ice (in contrast to Krämer et al.). 
Finally, we analyzed the profiles at slightly displaced geographical positions. The evolution of BSR in Fig. 5 suggests that both clouds underwent evaporation during the measurement. Therefore we checked whether COSMO-7 simply displaced the profiles and captured the situation shifted by $30 \mathrm{~km}$ to the north, east, south or west of Lindenberg. This analysis (not shown here) reveals that the upper cloud varies somewhat in altitude (by less than $1 \mathrm{~km}$ ) depending on the geographical position. This is an indication for waves in this region, as is also depicted in Fig. A2. Indeed, the model provides better agreement with the measurements when evaluated at $30 \mathrm{~km}$ south of Lindenberg (i.e. upstream), whereas the balloon drifted northward.

\section{Summary and conclusion}

This work has analyzed balloon-borne sonde measurements of two cirrus layers above Lindenberg, Germany, on 6 November 2008. The newly developed backscatter sonde COBALD and the frost point hygrometer $\mathrm{CFH}$ were used as part of the field campaign during the "Lindenberg Upper-Air Methods Intercomparison" (LUAMI). The COBALD-CFH tandem is shown to be an excellent combination to estimate the partitioning of atmospheric water between the gas phase and the condensed ice phase in and around cirrus clouds, and thus to detect in-cloud and out-of-cloud supersaturation with respect to ice. In-cloud measurements showed that $\mathrm{RH}_{\text {ice var- }}$ ied from $50 \%$ to $130 \%$, with supersaturations occurring at the cloud upper edges, and subsaturation at the cloud lower edges, reflecting the regions of fresh nucleation and particle evaporation in fall streaks, respectively. Aircraft-borne measurements have shown a similar range of $\mathrm{RH}_{\text {ice }}$ in the 210$230 \mathrm{~K}$ temperature regime (Krämer et al., 2009), therefore suggesting the absence of platform-specific biases.

In contrast to the too coarsely resolved ECMWF analysis data, COSMO-7 forecast fields $(6.6 \mathrm{~km} \times 6.6 \mathrm{~km}, 5 \mathrm{~min}$ resolution, Appendix C) show good agreement with the observations, though the cloud altitude and thus the profile of the ice water content are not captured accurately. Also, COSMO7 shows generally smaller in-cloud and out-of-cloud supersaturations than were observed by $\mathrm{CFH}$. Agreement can be improved by using comprehensive microphysical cloud model calculations along LAGRANTO trajectories based on COSMO-7 wind and temperature fields allow humidity, ice particle size, number density and backscatter ratios to be determined much more accurately than the COSMO-7 cloud scheme. However, satisfying agreement with the measurements can only be obtained after superimposing smallscale temperature fluctuations, $(d T / d t)_{s s}$, onto the COSMO7-based trajectories. In an ensemble model-calculation of 20 runs with randomly superimposed small-scale temperature fluctuations $(d T / d t)_{s s}$ in-cloud supersaturations of up to $30 \%$ are reached, which is in agreement with the measurements. In summary, the present study, although providing observa-

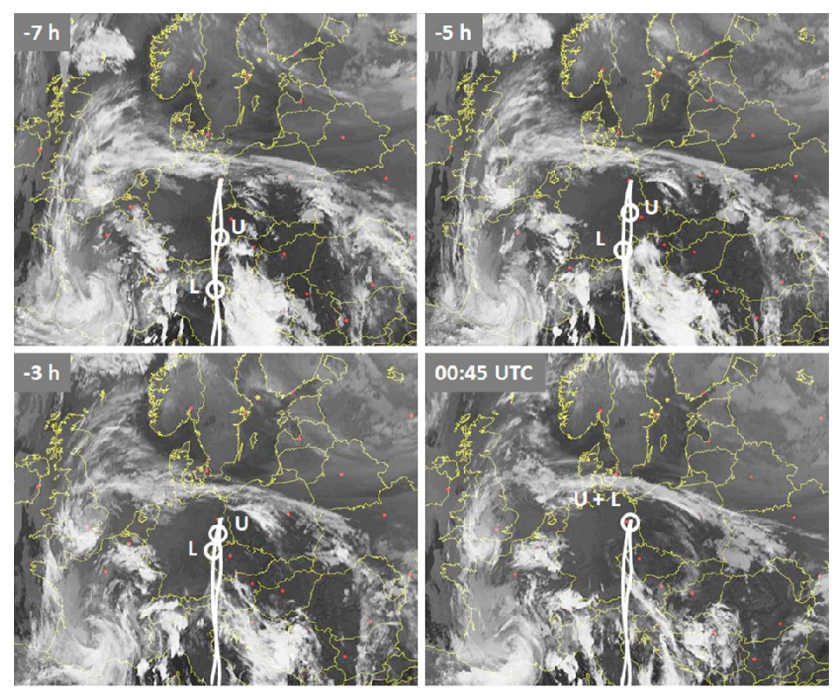

Fig. A1. Cloud images from the Meteosat satellite at four different times (Eumetsat, 2012). White lines: projections of the trajectories ending in the upper "U" and lower "L" cloud at 00:45 UTC. White circles: respective positions of air parcels $7 \mathrm{~h}, 5 \mathrm{~h}$ and $3 \mathrm{~h}$ upstream.
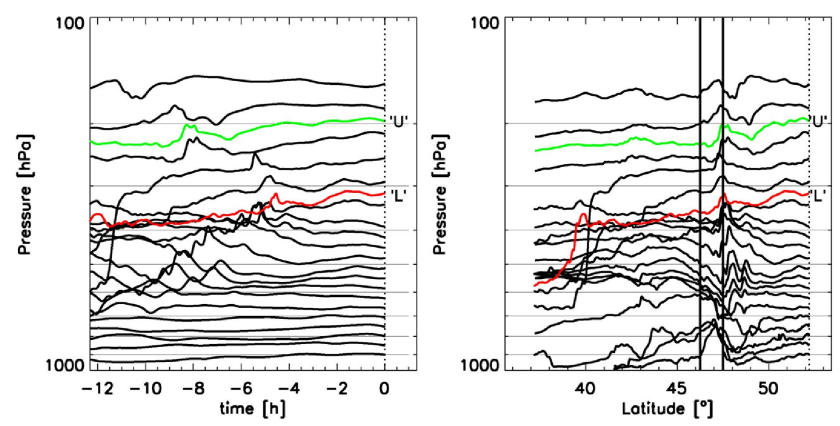

Fig. A2. Field of COSMO-7-based LAGRANTO trajectories highlighting the two trajectories ending in the lower cloud " $\mathrm{L}$ " (red) and upper cloud "U" (green). Left panel: trajectory pressure vs. time. Right panel: trajectory pressure vs. latitude. Waves are caused by the main chain of the Alps located around $47^{\circ} \mathrm{N}$ (indicated by vertical lines).

tional evidence for high in-cloud supersaturation, does not require heterogeneous nucleation, nor does it call for other, less well explored physical mechanisms to explain the apparent supersaturation.

\section{Appendix A}

\section{Upper tropospheric weather on 6 November 2008}

Figure A1 shows cloud images from the Meteosat-9 satellite at four different times during the night of 5-6 November 2008. The selected channel is the Thermal Infrared, IR $10.8 \mu \mathrm{m}$. The gray scale visualises temperatures. Bright regions indicate cold clouds, e.g. convective systems or 
outflows thereof. Conversely, very dark regions indicate clear sky. Grey tones indicate low-level clouds or fog. Fine differences in grey shading over northeastern Germany and western Poland suggest banks of low-level clouds or fog, such as the 400-m thick radiative fog layer prevailing in Lindenberg during this night. In contrast, the subvisible cirrus clouds measured by COBALD around 8.5 and $11.9 \mathrm{~km}$ remain undetectable for Meteosat. The white lines superimposed on the Meteosat images are projections of the two COSMO-7-based LAGRANTO trajectories ending in the lower and upper subvisible cirrus, "L" and "U", at 00:35 and 00:45 UTC, respectively. The white circles indicate the respective positions of air parcels at $-7 \mathrm{~h},-5 \mathrm{~h}$ and $-3 \mathrm{~h}$ upstream, eventually arriving at " $U$ " and "L" over Lindenberg. The absence of bright features in the vicinity of the air parcel positions suggests that the air has not been directly affected by convective outflow, rather has been subject to wave-driven cooling when the air is passing across the main chain of the Alps. The similar development of the two trajectories shows the absence of horizontal wind shear.

Figure A2 shows an altitude-resolved array of COSMO-7based LAGRANTO backward trajectories ending at the balloon flight path at time $t=0$ (around $52.2^{\circ} \mathrm{N}$ ). The two trajectories marked in red and green depict the air parcel paths ending in the lower cloud "L" and upper cloud "U", respectively. The left panel of Fig. A2 shows the gravity waves being assembled at different times, due to some vertical wind shear. The right panel shows the same trajectories but plotted as pressure vs. latitude, revealing the waves to be generated around $47^{\circ} \mathrm{N}$ at almost all altitudes. These waves are caused by the main chain of the Alps. The maximum wave activity is located around $47^{\circ} \mathrm{N}-13^{\circ} \mathrm{E}$, the region of the Upper Tauern, a West-East oriented mountain chain in Austria, which reaches up to $3800 \mathrm{~m}$ altitude. The absence of horizontal wind shear and the wind direction being almost orthogonal to the mountain ridge are ideal prerequisites for the development of the mountain-wave induced cirrus clouds.

\section{Appendix B}

\section{Estimation of the IWC from the measured ABSR}

Obtaining an estimate of the $I W C$ from the aerosol backscatter ratio $A B S R$ measured by COBALD is not possible in an exact manner, because the size distribution is generally not known. However, if the distribution can be approximated as lognormal with constant width $\sigma$ and if rough estimates of the mode radius $r_{\mathrm{m}}$ exist, an approximate IWC-ABSR relationship is readily obtained, including an error estimate. Figure B1 shows simulated $A B S R$ at wavelength $870 \mathrm{~nm}$ for $I W C=10^{-3} \mathrm{~g} \mathrm{~kg}^{-1}$ condensed as ice in a lognormal size distribution as function of $r_{\mathrm{m}}$. The assumed lognormal size distribution width is $\sigma=1.4$, the refractive index is that of

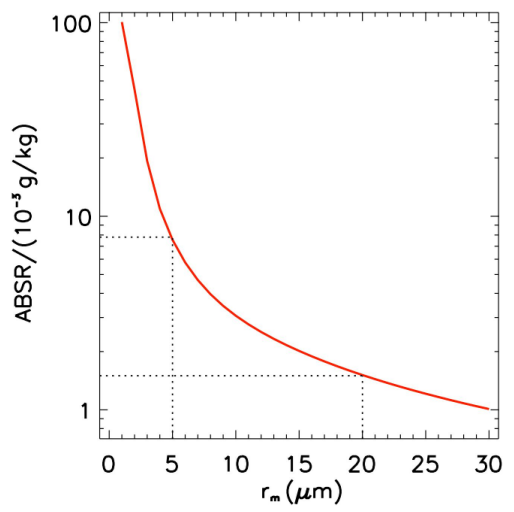

Fig. B1. Red curve: Simulated aerosol backscatter ratio $(A B S R)$ at $870 \mathrm{~nm}$ wavelength per $10^{-3} \mathrm{~g} \mathrm{~kg}^{-1}$ condensed as ice particles in a lognormal size distribution in dependence of the mode radius $\left(r_{\mathrm{m}}\right)$. The assumed conditions are a lognormal distribution width $\sigma=1.4$, a refractive index of 1.31 (for ice), and an aspect ratio $A=0.75$ for prolate spheroids as proxy for the ice particle asphericity. ABSR for $I W C$ other than $10^{-3} \mathrm{~g} \mathrm{~kg}^{-1}$ are obtained by appropriate scaling of the ordinate. Black dotted lines: typical range of $r_{\mathrm{m}}$ in high thin cirrus clouds (which formed in situ, e.g. by orographically forced upwelling), resulting in an overall uncertainty in $B S R$ of a factor of $\sim 4$.

ice (1.31), and the aspect ratio of the aspherical particles is $A=0.75$

An ice water content of $10^{-3} \mathrm{~g} / \mathrm{kg}$ corresponds to only $1.6 \mathrm{ppmv} \mathrm{H}_{2} \mathrm{O}$ in the condensed ice phase, i.e. a very thin subvisible cloud. This calculation is easily applied to higher condensed masses by multiplying the ordinate with the appropriate $I W C$. The calculation reveals a significant, but overall weak dependence on the mode radius $r_{\mathrm{m}}$. Typical values for $r_{\mathrm{m}}$ depend on the altitude and production process of the cirrus cloud. While cirrus decks from deep convective outflow may contain very large ice particles with radii larger than $100 \mu \mathrm{m}$, the clouds of interest here contain ice crystals with typical radii between $5 \mu \mathrm{m}$ and $20 \mu \mathrm{m}$. See for example the results from the microphysical box model calculations in Fig. B2, which belong to the model run shown in Fig. 5 and detailed in Sect. 6. The resulting range of ABSR corresponds to an overall uncertainty of a factor $\sim 4$ (dashed lines in Fig. B1).

Applying these considerations to the COBALD measurements in clouds "L" and "U" yields the blue points and error bars for $I W C$ in the lower panels of Fig. 2.

\section{Appendix C}

\section{5-min stored fields of COSMO-7}

A special research data set was assembled storing COSMO7 fields every $5 \mathrm{~min}$ instead of the usual hourly storage. This was done after it had become clear that the quality 

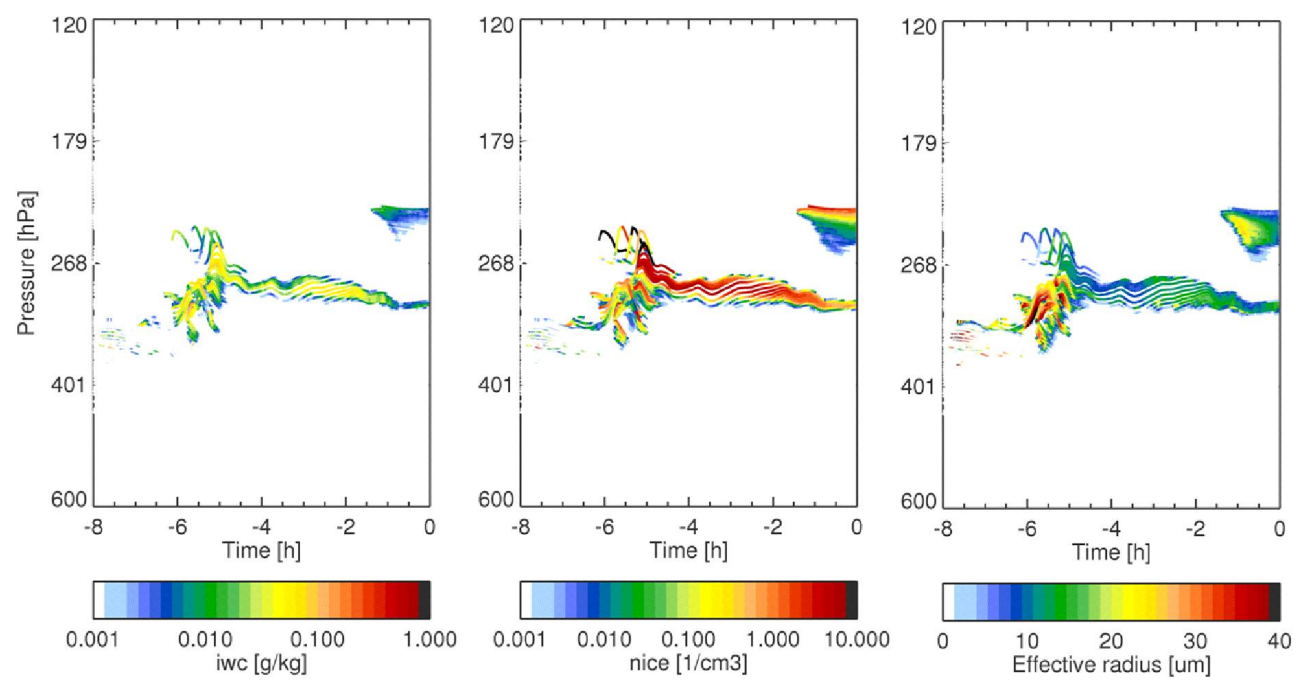

Fig. B2. Microphysical column model results for the case with superimposed small-scale temperature fluctuations showing parameters in addition to those shown in Fig. 5. Left panel: ice water content, IWC. Centre panel: ice number density, $n_{\text {ice }}$. Right panel: effective radius of the ice crystals, $r_{\text {eff. }}$

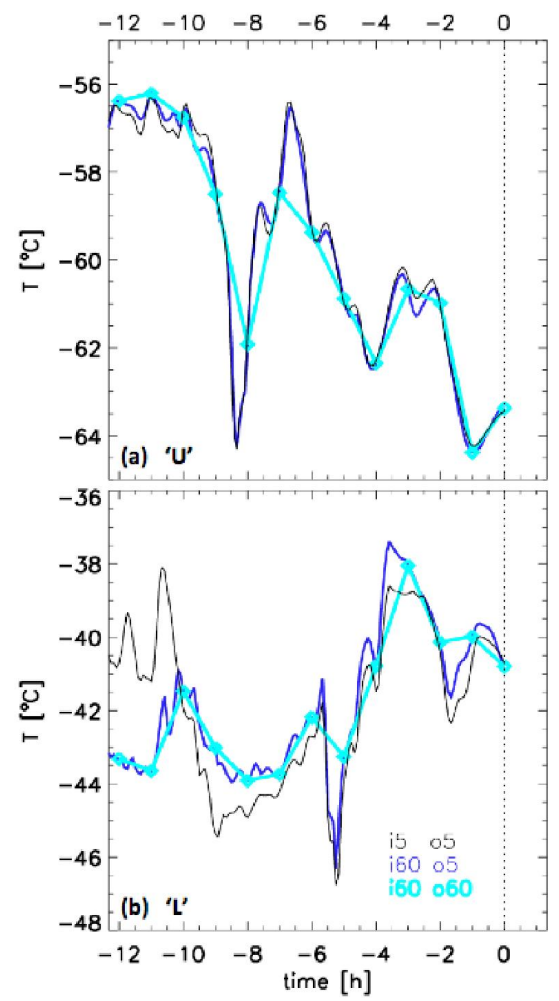

Fig. C1. Examples of backward trajectories for (a) the upper cloud "U”, (b) lower cloud "L". Black curves: based on COSMO-7 fields with 5-min resolution, providing trajectory values every 5 min. Dark blue curves: based on COSMO-7 fields with 1-h resolution, interpolating trajectory values every $5 \mathrm{~min}$. Cyan curves: based on COSMO-7 fields with 1-hour resolution, providing trajectory values every $1 \mathrm{~h}$. of the microphysical model will depend crucially on capturing the correct cooling rates, i.e. small-scale temperature fluctuations, $(d T / d t)_{s s}$. We used this opportunity to examine whether the high spatial or the high temporal resolution is more important for providing the meteorological conditions required for the ice cloud microphysics. Figure $\mathrm{C} 1$ shows for both the upper ('U') and lower ("L') cloud the LAGRANTO-derived backward trajectories, either based on the 5-min wind fields as input and 5-min trajectory output (black lines) or based on hourly wind fields, which are simply a subset of the 5-min dataset (bluish lines). The 1-h-based trajectory data show either also the interpolated data (dark blue) or only the 1-h data (cyan). The interpolated data (dark blue) provide cooling and heating rates which are comparable to the 5-min based dataset, much better than those trajectory data providing only the hourly trajectory data. This suggests that interpolating trajectory data is actually a microphysically sensible procedure, even though the interpolation is of course not fully accurate. The reason for this benign behaviour is that trajectories pick up the high spatial resolution of COSMO-7 $(6.6 \mathrm{~km} \times 6.6 \mathrm{~km})$, including orography and weather systems, even when the temporal storage is only hourly. Horizontal winds chase the air parcels much faster across this texture than the texture changes itself as function of time, at least in the cases examined here.

Acknowledgements. M. Brabec has been funded by the Swiss National Science Foundation under project number 2000211179879. We also acknowledge ETH, Zurich, for financial support. Thanks to the organizers of the "Lindenberg Upper-Air Methods Intercomparison" campaign (LUAMI) and the whole crew in Lindenberg for excellent campaign work. We thank the European Centre for Medium Range Weather Forecast for the use of ECMWF 
analysis data. We gratefully acknowledge Petra Baumann from MeteoSwiss for the computation of the COSMO-7 weather forecasts performed at the Swiss National Supercomputing Centre (CSCS) in Manno, Switzerland. For LAGRANTO support we would like to acknowledge Michael Sprenger from ETH. We also gratefully acknowledge EUMETSAT for the satellite images. Finally, we thank Dr. Rob MacKenzie and an anonymous referee for their very useful comments on the ACP Discussion paper.

Edited by: G. Vaughan

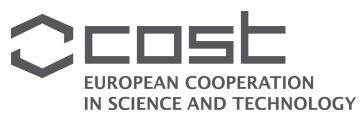

This publication is supported by COST - www.cost.eu

\section{References}

Beyerle, G., Gross, M., Haner, D., Kjome, N., McDermid, I., McGee, T., Rosen, J., Schäfer, H.-J., and Schrems, O.: A lidar and backscatter sonde measurement campaign at Table Mountain during February-March 1997: Observations of cirrus clouds, J. Atmos. Sci., 58, 1275-1287, 2001.

Carslaw, K. S., Wirth, M., Tsias, A., Luo, B. P., Dörnbrack, A., Leutbecher, M., Volkert, H., Renger, W., Bacmeister, J. T., and Peter, T.: Particle microphysics and chemistry in remotely observed mountain polar stratospheric clouds, J. Geophys. Res., 103, 5785-5796, 1998.

Christensen, J.H., Hewitson, B., Busuioc, A., Chen, A., Gao, X., Held, I., Jones, R., Kolli, R.K., Kwon, W.T., Laprise, R., Magaña Rueda, V., Mearns, L., Menéndez, C.G., Räisänen, J., Rinke, A., Sarr A. and Whetton, P.: Regional Climate Projections. In: Climate Change 2007: The Physical Science Basis. Contribution of Working Group I to the Fourth Assessment Report of the Intergovernmental Panel on Climate Change, edited by: Solomon, S., Qin D., Manning, M., Chen, Z., Marquis, M., Averyt, K. B., Tignor, M., and Miller, H. L., Cambridge University Press, Cambridge, United Kingdom and New York, NY, USA, 2007.

Colberg, C. A., Luo, B. P., Wernli, H., Koop, T., and Peter, T.: A novel model to predict the physical state of atmospheric $\mathrm{H}_{2} \mathrm{SO}_{4} / \mathrm{NH}_{3} / \mathrm{H}_{2} \mathrm{O}$ aerosol particles, Atmos. Chem. Phys., 3, 909-924, doi:10.5194/acp-3-909-2003, 2003.

Di Donfrancesco, G., Cairo, F., Buontempo, C., Adriani, A., Viterbini, M., Snels, M., Morbidini, R., Piccolo, F., Cardillo, F., Pommereau, J.-P., and Garnier, A.: Balloonborne lidar for cloud physics studies, Appl. Opt., 45, 5701-5708, 2006.

Doms, G., Förstner, J., Heise, E., Herzog, H.-J., Mironov, D., Raschendorfer, M., Reinhardt, T., Ritter, B., Schrodin, R., Schulz, J.-P. and Vogel, G.: A description of the nonhydrostatic regional COSMO model, Part II: Physical parameterization, Deutscher Wetterdienst, P.O. Box 100465, 63004 Offenbach, Germany, http://www.cosmo-model.org/content/model/ documentation/core/default.ht, 2011 (last access on 25 August 2012).

Durry, G., Huret, N., Hauchecorne, A., Marecal, V., Pommereau, J.P., Jones, R.L., Held, G., Larsen, N., and Renard, J.-B.: Isentropic advection and convective lifting of water vapor in the UT - LS as observed over Brazil $\left(22^{\circ} \mathrm{S}\right)$ in February 2004 by in situ highresolution measurements of $\mathrm{H}_{2} \mathrm{O}, \mathrm{CH}_{4}, \mathrm{O}_{3}$ and temperature, At- mos. Chem. Phys. Discuss., 6, 12469-12501, doi:10.5194/acpd6-12469-2006, 2006.

EUMETSAT, Monitoring weather and climate from space, www. eumetsat.int, (last access: 16 March 2012), 2012.

Fierli, F., Di Donfrancesco, G., Cairo, F., Marécal, V., Zampieri, M., Orlandi, E. and Durry, G.: Variability of cirrus clouds in a convective outflow during the Hibiscus campaign, Atmos. Chem. Phys., 8, 4547-4558, doi:10.5194/acp-8-4547-2008, 2008.

Fu, Q.: A new parameterization of an asymmetry factor of cirrus clouds for climate models, J. Atmos. Sci., 64, 4140-4150, 2007.

Fueglistaler, S., Wernli, H., and Peter, T.: Tropical troposphereto-stratosphere transport inferred from trajectory calculations, J. Geophys. Res., 109, D03108, doi:10.1029/2003JD004069, 2004.

Hoyle, C. R., Luo, B. P., and Peter, T.: The origin of high ice crystal number densities in cirrus clouds. J. Atmos. Sci., 62, 2568-2579, 2005.

Jensen, E. J., Pfister, L., Bui, T.-P. Bui, Lawson, P., Baker, B., Mo, Q., Baumgardner, D., Weinstock, E. M., Smith, J. B., Moyer, E.J. Moyer, Hanisco, T. F., Sayres, D. S., St. Clair, J. M., Alexander, M. J., Toon, O. B., and Smith, J. A.: Formation of large $(\approx 100 \mu \mathrm{m})$ ice crystals near the tropical tropopause, Atmos. Chem. Phys., 8, 1621-1633, doi:10.5194/acp-8-1621-2008, 2008.

Joos, H., Spichtinger, P., Lohmann, U., Gayet, J.-F., and Minikin, A.: Orographic cirrus in the global climate model ECHAM5, J. Geophys. Res., 113, D18205, doi:10.1029/2007JD009605, 2008.

Kahn, B.H., Gettelman, Fetzer, A. E., Eldering, J. A., and Liang, C. K.: Cloudy and clear-sky relative humidity in the upper troposphere observed by the A-train, J. Geophys. Res., 114, D00H02, doi:10.1029/2009JD011738, 2009.

Kärcher, B. and Lohmann, U.: A parameterization of cirrus cloud formation: Heterogeneous freezing, J. Geophys. Res., 108, 4402, doi:10.1029/2002JD003220, 2003.

Koop, T., Luo, B., Tsias, A., and Peter, T.: Water activity as the determinant for homogeneous ice nucleation in aqueous solutions, Nature, 406, 611-614, 2000.

Krämer, M., Schiller, C., Afchine, A., Bauer, R., Gensch, I., Mangold, A., Schlicht, S., Spelten, N., Sitnikov, N., Borrmann, S., de Reus, M. and Spichtinger, P.: Ice supersaturations and cirrus cloud crystal numbers, Atmos. Chem. Phys., 9, 3505-3522, doi:10.5194/acp-9-3505-2009, 2009.

Larsen, N., Knudsen, B., Jorgensen, T. S., di Sarra, A., Fuà, D., Di Girolamo, P., Fiocco, G., Cacciani, M., Rosen, J., and Kjome, N.: Backscatter measurements of stratospheric aerosols at Thule during January-February 1992. Geophys. Res. Lett., 21, 13031306, 1994.

Luo, B. P., Peter, T., Fueglistaler, S., Wernli, H., Wirth, M., Kiemle, C., Flentje, H., Yushkov, V. A., Khattatov, V., Rudakov, V., Thomas, A., Borrmann, S., Toci, S. G, Mazzinghi, P., Beuermann, J., Schiller, C., Cairo, F., Di Donfrancesco, G., Adriani, A., Volk, C. M., Strom, J., Noone, K., Mitev, V., MacKenzie, R. A., Carslaw, K. S., Trautmann, T., Santacesaria, V., and Stefanutti, L.: Dehydration potential of ultrathin clouds at the tropical tropopause, Geophys. Res. Lett., 30, 1557, doi:10.1029/2002GL016737, 2003a.

Luo, B. P., Voigt, C., Fueglistaler, S., and Peter, T.: Extreme NAT supersaturations in mountain wave ice PSCs: A clue to NAT formation. J. Geophys. Res., 108, 4441, doi:10.1029/2002JD003104, 2003b. 
MacKenzie, A. R. and Haynes, P. H.: The influence of surface kinetics on the growth of stratospheric ice crystals, J. Geophys. Res., 97, 8057-8064, 1992.

MeteoSwiss: The numerical weather prediction model COSMO, website available under http://www.meteoswiss.admin.ch/web/ en/weather/models/cosmo.html, last access: 30 January 2012.

Mishchenko, M. I.: Light scattering by randomly oriented axially symmetric particles, J. Opt. Soc. Am., 8, 871-882, 1991.

Möhler, O., Fahey, D., and Gao, R.: Summary of the aquavit water vapor intercomparison: Static experiments, 2009, website available at: https://aquavit.icg.kfajuelich.de/whitepaper, (last access: 1 August 2012), 2012.

Murray, B. J., Wilson, T. W., Dobbie, S., Cui, Z., Al-Jumur, S. M. R. K., Möhler, O., Schnaiter, M., Wagner, R., Benz S., Niemand, M., Saathoff, H., Ebert, V., Wagner, S., and Kärcher, B.: Heterogeneous nucleation of ice particles on glassy aerosols under cirrus conditions, Nature Geosci., 3, doi:10.1038/NGEO817, 2010.

Nousiainen, T. and McFarquhar, G. M.: Light scattering by quasi-spherical ice crystals, J. Atmos. Sci., 61, 2229-2248, doi:10.1175/1520-0469(2004)061<2229:LSBQIC > 2.0.CO;2, 2004.

Peter, T., Marcolli, C., Spichtinger, P., Corti, T., Baker, M. B., and Koop, T.: When Dry Air Is Too Humid, Science, 314, 1399_ 1402, 2006.

Pommereau, J.-P., Garnier, A., Held, G., Gomes, A. M., Goutail, F., Durry, G., Borchi, F., Hauchecorne, A., Montoux, N., Cocquerez, P., Letrenne, G., Vial, F., Hertzog, A., Legras, B., Pisso, I., Pyle, J. A., Harris, N. R. P., Jones, R. L., Robinson, A. D., Hansford, G., Eden, L., Gardiner, T., Swann, N., Knudsen, B., Larsen, N., Nielsen, J. K., Christensen, T., Cairo, F., Fierli, F., Pirre, M., Marécal, V., Huret, N., Riviére, E. D., Coe, H., Grosvenor, D., Edvarsen, K., Di Donfrancesco, G., Ricaud, P., Berthelier, J.-J., Godefroy, M., Seran, E., Longo, K., and Freitas, S.: An overview of the HIBISCUS campaign, Atmos. Chem. Phys., 11, 23092339, doi:10.5194/acp-11-2309-2011, 2011.

Rosen, J. M. and Kjome, N. T.: Backscattersonde: a new instrument for atmospheric aerosol research, Appl. Opt., 30, 1552-1561, 1991.

Rosen, J. M., Kjome, N. T., and Liley, B.: Tropospheric aerosol backscatter at a midlatitude site in the northern and southern hemispheres, J. Geophys. Res., 21329-21339, 1997.

Sassen, K.: Cirrus Clouds, edited by: Lynch, D. K., Sassen, K., Starr, D. O., and Stephens, G., in: Cirrus, Oxford University Press, 11-40, 2002.
Seinfeld, J. and Pandis, S.: Atmospheric Chemistry and Physics: From Air Pollution to Climate Change, Wiley-Interscience, New York, USA, 1326 pp., 1998.

Spichtinger, P., Gierens, K., and Dörnbrack, A.: Formation of ice supersaturation by mesoscale gravity waves, Atmos. Chem. Phys., 5, 1243-1255, doi:10.5194/acp-5-1243-2005, 2005a.

Spichtinger, P., Gierens, K., and Wernli, H.: A case study on the formation and evolution of ice supersaturation in the vicinity of a warm conveyor belt's outflow region, Atmos. Chem. Phys., 5, 973-987, doi:10.5194/acp-5-973-2005, 2005b.

Spichtinger, P. and Cziczo, D. J.: Impact of heterogeneous ice nuclei on homogeneous freezing events in cirrus clouds, J. Geophys. Res., 115, doi:10.1029/2009JD012168, 2010.

Steppeler, J., Doms, G., Schättler, U., Bitzer, H. W., Gassmann, A., Damrath, U., and Gregoric, G.: Meso-gamma scale forecasts using the nonhydrostatic model LM, Meteorol. Atmos. Phys. 82, 75-96, 2003.

Thornberry, T., Gierczak, T., Gao, R. S., Vömel, H., Watts, L. A., Burkholder, J. B., and Fahey, D. W.: Laboratory evaluation of the effect of nitric acid uptake on frost point hygrometer performance, Atmos. Meas. Tech., 4, 289-296, doi:10.5194/amt-4289-2011, 2011.

Tompkins, A. M., Gierens, K., and Rädel, G.: Ice supersaturation in the ECMWF integrated forecast system, Q. J. Roy. Meteorol. Soc., 133, 53-63, 2007.

Vömel, H., David, D., and Smith, K.: Accuracy of tropospheric and stratospheric water vapor measurements by cryogenic frost point hygrometer: Instrumental details and observations. J. Geophys. Res., 112, D08305, doi:10.1029/2006JD007224, 2007.

Wernli, H. and Davies, H.: A lagrangian-based analysis of extratropical cyclones. I: The method and some applications, Q. J. Roy. Meteorol. Soc., 123, 467-489, 1997.

Wiederhold, P.: Water vapor measurement: methods and instrumentation. Marcel Dekker, Inc., 353 pp., 1997.

Wienhold, F. G.: COBALD (Compact Optical Backscatter Aerosol Detector) Data Sheet, http://www.iac.ethz.ch/groups/ peter/research/Balloon_soundings/COBALD_data_sheet, last accessed on 26 December 2011.

Zobrist, B., Koop, T., Luo, B. P., Marcolli, C., and Peter T.: Heterogeneous Ice Nucleation Rate Coefficient of Water Droplets Coated by a Nonadecanol Monolayer, J. Phys. Chem. C, 111, 21490-2155, 2007. 